\title{
Evaluation of Mesocyclops annulatus (Copepoda: Cyclopoidea) as a Control Agent of Aedes aegypti (Diptera: Culicidae) in Argentina
}

\author{
Gerardo A Marti, Maria V Micieli ${ }^{+}$, Ana C Scorsetti, Gerardo Liljesthröm
}

Centro de Estudios Parasitológicos y de Vectores, Conicet-UNLP, Calle 2 nº 584 (1900) La Plata, Argentina

We evaluated the potential of Mesocyclops annulatus as a control agent of Aedes aegypti in La Plata city (Argentina). Mosquito larval survivorship due to predation by these copepods was estimated at weekly intervals during the oviposition period of A. aegypti. Mean weekly A. aegypti larval survivorship in cylindrical plastic containers (12 cm height and $11 \mathrm{~cm}$ diameter) with copepods was significantly lower than in control containers. Furthermore, weekly larval survival was negatively correlated with $\mathrm{M}$. annulatus adult density, and approximately 23 adult copepods/container would be a threshold density over which the weekly mosquito larval survivorship approached zero. The copepods were able to persist in all containers during approximately 100 days (in three of them until the end of the experiment: 155 days) without the resource represented by $\mathrm{A}$. aegypti larvae. The predation and persistence observed suggest that $\mathrm{M}$. annulatus is a potential control agent to be considered in biological control programs.

Key words: Aedes aegypti - Culicidae - Mesocyclops annulatus - copepoda - larval predation - biological control - Argentina

Aedes (Stg.) aegypti (L.) is the main dengue vector in America, and there has been a marked increase in the number of human infections associated with its spreading geographical distribution. Haemorrhagic and "classic" dengue epidemics were registered in several countries of Central and South America during the last three decades (OPS 1995). In Argentina A. aegypti reappeared in 1986 (OPS 1990). Nowadays its distribution has spread throughout 15 provinces (Curto et al. 2002), and "classic" dengue cases have been detected since 1997 (Aviles et al. 1999).

The integrated control of $A$. aegypti emphasizing the biological control of larvae by predators and parasites is a desirable alternative strategy to the traditional use of insecticides, due to the development of resistance and the negative impact on the environment (Molyneux 1993). Cyclopoid copepods are important predators of early-instar A. aegypti larvae (Marten 1990, Marten et al. 1994). Inoculative copepod releases in natural and artificial small water containers at urbanized areas significantly reduced the population abundance of $A$. aegypti (Gorrochotegui et al. 1998, Schaper 1999).

In Argentina, the copepod Mesocyclops annulatus (Wierzejski) has been found inhabiting natural temporary pools, and as other copepod species (Zhen et al. 1994), it is capable of persisting, at least as adults, during unfavorable periods when these pools remain dried up (García \& Micieli 1999). In laboratory conditions M. annulatus feeds on algae, protozoan, and on the first and the second larval instars of A. aegypti and Culex pipiens L. and

Financial support: Consejo Nacional de Investigaciones Científicas y Técnicas de Argentina

${ }^{+}$Corresponding author. Fax: +54-0221-423.2327. E-mail: vmicieli@museo.fcnym.unlp.edu.ar

Received 16 January 2004

Accepted 28 July 2004 due to the benthic habit of $A$. aegypti larvae, this species was preferentially predated (Micieli et al. 2002).

We evaluated the potential of $M$. annulatus as a control agent of $A$. aegypti considering the reduction of mosquito larval survivorship due only to predation by $M$. annulatus, and the persistence of the copepod during mid spring-late summer seasons, period when oviposition by $A$. aegypti takes place in the area.

\section{MATERIALS AND METHODS}

The containers used in the experiments represent one of the breeding sites of $A$. aegypti in the area (García et al. 2002).

We conducted the trials in an experimental garden of Cepave in La Plata city (34 $51^{\circ} 07^{\prime \prime}$ S-58 $\left.57^{\prime} 30^{\prime \prime} \mathrm{W}\right)$, Buenos Aires province, Argentina.

In mid September, the upper edges of 12 cylindrical plastic containers (12 cm height, $11 \mathrm{~cm}$ diameter, $700 \mathrm{ml})$ were covered with strips of rough paper ( $5 \mathrm{~cm}$ wide) as substratum for A. aegypti oviposition. Each container was filled with water $(500 \mathrm{ml})$ up to the edge of paper. The containers had holes to allow washing up during heavy rains to keep the volume approximately at $500 \mathrm{ml}$. The containers were left in the open and no food was added. In order to avoid desiccation, the water level was controlled at weekly intervals.

Twenty $M$. annulatus adult gravid females from a Cepave culture (Micieli et al. 2002) were added a month later to each one of six containers selected at random, whereas the other six containers were considered as control. The experiment lasted 155 days, from mid spring up to the end of the summer period (25 October - 29 March 2001), during which oviposition by A. aegypti takes place in this region of the country (Garcia et al. 2002).

We do not know the dispersal capabilities of $M$. annulatus. We though that due to the relative isolation of the experimental garden, possible recolonizations of the containers by $M$. annulatus would be negligible allowing for persistence evaluation (the evaluation was only con- 
sidered if no copepod were found in the control containers).

The number of eggs (on the strip of paper), larvae, and pupae of A. aegypti and the number of juvenile and adult copepods in each container were registered weekly in the laboratory. For that purpose, the water in each container was emptied into a plastic tray. After recording the data, the water and all the individuals were put back in the container and the strip of paper was replaced by a new one. Dechlorinated water was added if necessary. To allow A. aegypti eggs to hatch, the strip of paper with the eggs was flooded and retrieved after 2-4 days. Identification of larval instars of A. aegypti was done according to Lane (1953) and Darsie and Mitchell (1985).

We expressed density in terms of the number of individuals per container.

Weekly larval survivorship between census $t-1$ and $t$ in container $j, \mathrm{SC}(t, j)$, was estimated for the containers with copepods, $\mathrm{SC}(t, j)=\mathrm{LO}(t, j) / \Sigma_{\mathrm{i}=1, . ., \mathrm{n}} \mathrm{H}(t-\mathrm{i}, j)$; where $\mathrm{LO}(t, j)$ represents the number of larvae and pupae observed and $\mathrm{H}(t-\mathrm{i}, j)$ represents the number of eggs of $A$. aegypti registered in census $t-\mathrm{i}(\mathrm{i}=1, \ldots, \mathrm{n})$ which, depending on their rate of development and the mean daily temperature, would be found as larvae or pupae in the $t$-th census (assuming 100\% survivorship). Since the daily oviposition distribution was unknown, we divided the total number of eggs in the census $t$ by the number of days in the interval, producing a uniform distribution. The degree of development attained at successive days within a given developmental stage was estimated as $\Sigma_{k=1, \ldots, \mathrm{m}} A(\mathrm{~T}(k)$ $T U$ ), where $A$ represents the daily rate of development at a given temperature, $\mathrm{T}(k)$ represents the mean daily temperature, $T U$ the threshold temperature, and summatory extends up to the day $k$ when $\Sigma_{k=1 \ldots, \mathrm{m}} A(\mathrm{~T}(k)-T U)=1$. For the egg stage $A=0.0237$ and $T U U^{\prime}=14.26^{\circ} \mathrm{C}$ (Christopher 1960, Tun-Lin et al. 2000), and for the larval stage $A=$ 0.0055 and $T U=10^{\circ} \mathrm{C}$ (Rueda et al. 1990). In case of total copepod disappearance in a given container, this was eliminated. Also, the mean preimaginal survivorship of $A$. aegypti in all containers was estimated as $\operatorname{SCM}(t)=\Sigma_{\mathrm{t}=1}$. ${ }_{\mathrm{N}} \mathrm{SC}(t, j) / \mathrm{J}$ (where $\mathrm{J}=6$, represents the total number of containers with copepods).

Similar calculations were made for the control containers, $\operatorname{ST}(t, j)$, and $\operatorname{STM}(t)$.

If water level declined between two successive censuses, a proportion of the wall container not covered by the paper could have been used by A. aegypti as an oviposition site. However, if heavy rains occurred during the interval, the water level would increase allowing the eggs to hatch. In this case the eggs would not be registered in our samplings, and the number of larvae censed at the end of the interval could have been greater than the number of eggs censed at the beginning. In this case, if $\mathrm{SC}(t$, $j)$ [or ST $(t, j)]>1$, it was considered that $\mathrm{SC}(t, j)[\operatorname{or~ST}(t, j)]$ $=1$.

Mean preimaginal survivorship, $\operatorname{SCM}(t)$ and $\operatorname{STM}(t)$, were compared under the null hypothesis of lack of differences between both series, while the alternative hypothesis postulated that $\operatorname{SCM}(t)<\operatorname{STM}(t)$. The significance was tested by the non parametric U (Mann-Whitney) test (Sokal \& Rohlf 1979).
The reduction of mosquito larval survivorship due only to predation by $M$. annulatus was estimated as SC $(t, j) / \operatorname{STM}(t)$.

Possible effects of adult copepod density were analyzed by plotting $A$. aegypti larval survivorship in sample $t$, on adult copepod density at the beginning of the interval (i.e. in the previous sample), C(t-1). Since both variables were estimated with error, a correlation analysis was made under the hypothesis of a negative correlation between the variables. Both $\mathrm{SC}(t, j)$ as well as $\operatorname{SC}(t, j) / \operatorname{STM}(t)$ were used as larval survivorship estimations.

Copepod persistence was estimated as the ratio between the number of containers in which at least one juvenile or adult $M$. annulatus was registered at the end of the experiment, and the initial number of containers with copepods. Also, the mean time of persistence of copepods was estimated as: $\mathrm{TM}=\left[\Sigma_{\mathrm{t}=1, \mathrm{~N}-1}\left(\Sigma_{\mathrm{j}=1, \mathrm{~J}} \mathrm{R}(j) \mathrm{K}(t)\right)\right]$ $/ \mathrm{J}$; where $\mathrm{R}(j)$ takes the values 1 or 0 when in the container $j$ at least one copepod was registered or not, respectively; $\mathrm{K}(t)$ represents the number of days between two successive censuses, $t$ and $t+1$, and $\mathrm{N}$ represents the total number of censuses.

\section{RESULTS}

Mean daily temperature fluctuated between 17 and $28^{\circ} \mathrm{C}$ during the experiment, and the mean temperature was $22.9^{\circ} \mathrm{C}$.

The first $A$. aegypti oviposition was detected by mid November and the last one by the end of the experiment (March 29). In this way, the time between the first and the last oviposition was 136 days, however mostly of them occurred in a period of 60 days, approximately, from mid January to March. The mean total number of eggs registered in the containers with copepods and in the control were, respectively, $376 \mathrm{eggs} / \mathrm{container}$ and $186.5 \mathrm{eggs} /$ container $\left(\mathrm{t}_{(10 \mathrm{gl})}=2.5(0.02<\mathrm{P}<0.05)\right.$. The larvae were detected from mid January up to the end of the experiment (Fig. 1a,b). The higher larval density occurred from February 9 up to the end of the experiment (Tables I, II).

No copepod was registered in the control containers during the experiment.

In four control containers and during 10 intervals it was found that $\operatorname{ST}(t, j)>1$, and $\operatorname{STM}(t)>1$ in four intervals. On the other hand, in the containers with copepods $\mathrm{SC}(t, j)<1$ in all containers and during all intervals, and consequently $\operatorname{SCM}(t)<1$ during all intervals. Mean preimaginal survivorship in the containers with copepods, $\operatorname{SCM}(t)$, was significantly lower than $\operatorname{STM}(t): \mathrm{U}=4$ $(\mathrm{n} 1=\mathrm{n} 2=8), \mathrm{P}=0.001$ (Fig. 2).

Fig. 3 shows the estimated reduction of mosquito larval survivorship due only to predation by $M$. annulatus, $\mathrm{SC}(t, j) / \mathrm{STM}(t)$, and the corresponding estimated copepod density at the beginning of the interval, $\mathrm{C}(t-1, j)$. The correlation coefficient was negative and significantly different from $0\left(\mathrm{r}=-0.67(\mathrm{n}=44) ; \mathrm{t}_{(42 \mathrm{gl})}=-5.85 ; \mathrm{P}<0.001\right)$.

The observed relationship suggests that mosquito larval survivorship would be zero when copepod density reaches at least 23 adults/container. In container 2 (which exhibited the lowest copepod density) the cumulated number of mosquito eggs was 283 and that of larvae and pupae was 265. In container 4 (which exhibited the highest 


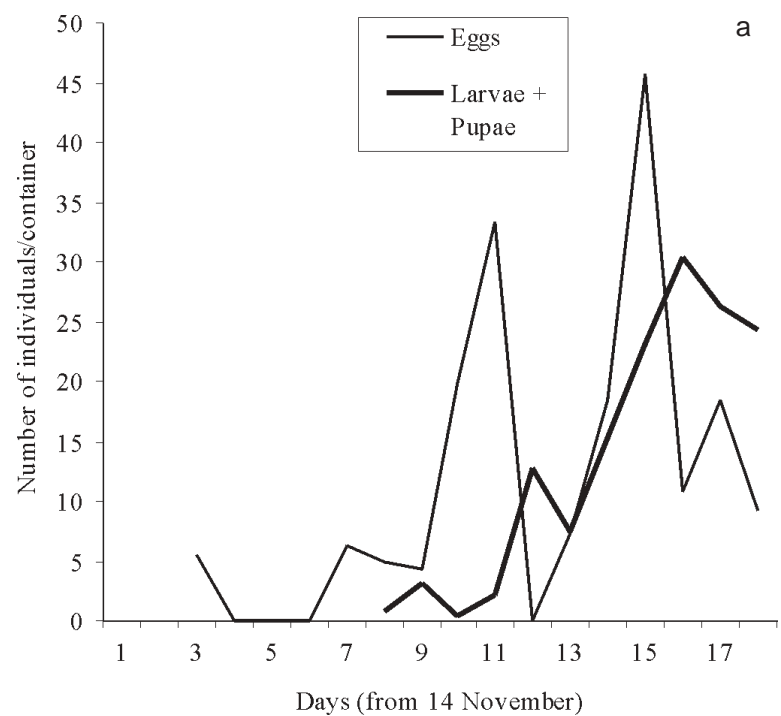

b

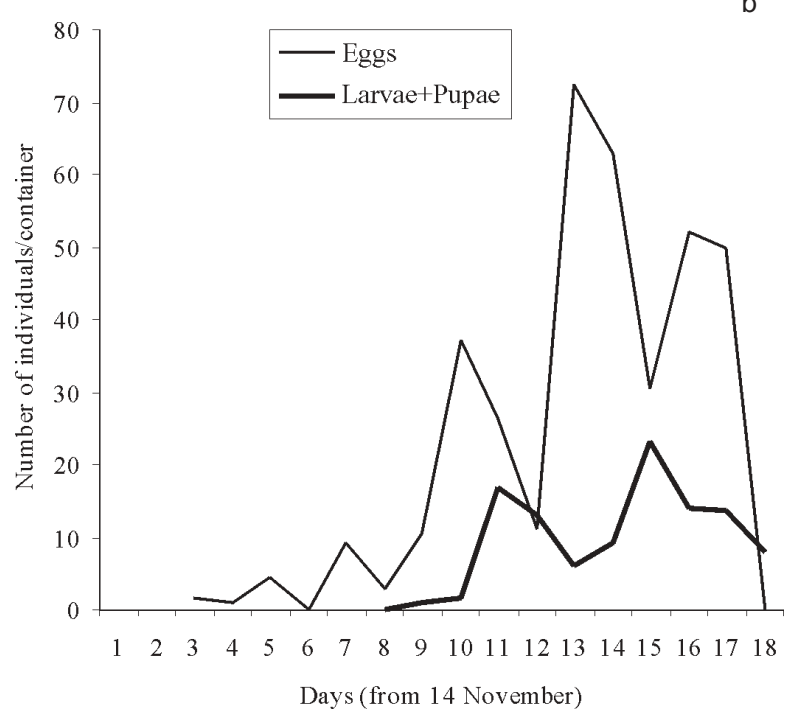

Fig. 1a: weekly mean density of eggs, larvae and pupae of Aedes aegypti during the experiments in control containers; b: containers with copepods

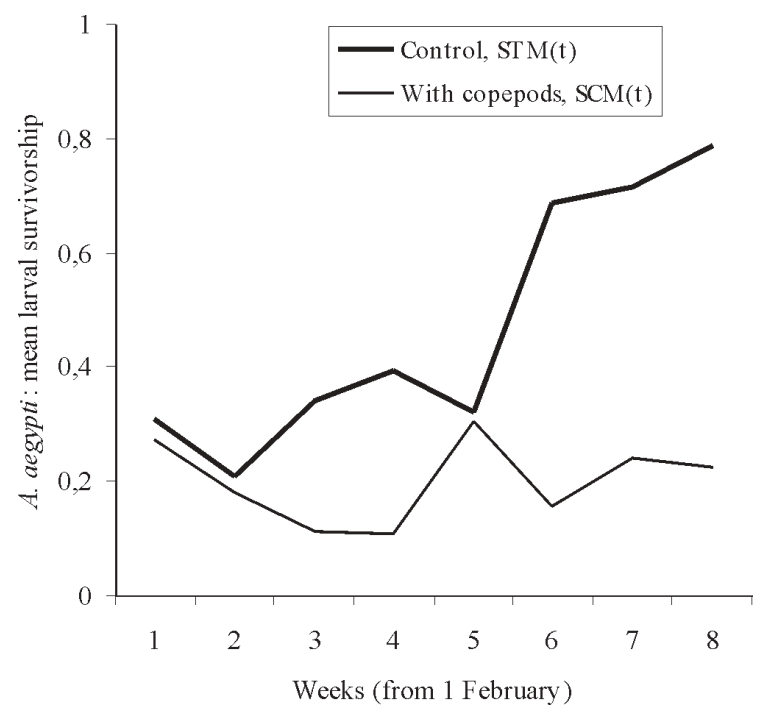

Fig. 2: mean preimaginal survivorship of Aedes aegypti larvae in control containers, STM $(t)$, and in containers with copepods, $\operatorname{SCM}(t)$.

copepod density) the corresponding values were 264 and 12.

The copepods persisted in all containers during 121 days (until March 15), exhibiting 100\% spatial coincidence and $88.9 \%$ synchrony at the interval during which $A$. aegypti ovipositions were registered. After that, the copepods persisted in five containers ( $83 \%$ spatial coincidence), and by the end of the experiment there were copepods in only three containers (50\% spatial coincidence).

The mean time of copepods persistence was $\mathrm{TM}=$ 158.7 days, and given that mosquito larvae were registered from January 18, the copepods persisted in all containers without the resource represented by $A$. aegypti larvae during 100 days (from October 13).

The mean copepod adult density fluctuated between 26.5 individuals/container (120 days after the beginning of the experiment when ovipositions by A. aegypti were registered for the first time) and 10.5 individuals/container by the end of the experiment. In container 2, adult cope-

\section{TABLE I}

Mean number of eggs (E), larvae and pupae (L), of Aedes aegypti per container $(\mathrm{C})$ in the controls during the period of higher mosquito larval density, from which $\operatorname{ST}(t, j)$ and $\operatorname{STM}(t)$

\begin{tabular}{|c|c|c|c|c|c|c|c|c|c|c|c|c|}
\hline \multirow[t]{2}{*}{ Date } & \multicolumn{2}{|c|}{ C 1} & \multicolumn{2}{|c|}{ C 2} & \multicolumn{2}{|c|}{ C 3} & \multicolumn{2}{|c|}{ C 4} & \multicolumn{2}{|c|}{ C 5} & \multicolumn{2}{|c|}{ C 6} \\
\hline & $\mathrm{E}$ & $\mathrm{L}$ & $\mathrm{E}$ & $\mathrm{L}$ & $\mathrm{E}$ & $\mathrm{L}$ & $\mathrm{E}$ & $\mathrm{L}$ & E & $\mathrm{L}$ & $\mathrm{E}$ & $\mathrm{L}$ \\
\hline 01-Feb & 4 & 1 & 2 & 0 & 13 & 0 & 60 & 0 & 0 & 0 & 40 & 0 \\
\hline 07-Feb & 73 & 4 & 0 & 1 & 0 & 1 & 60 & 7 & 0 & 0 & 0 & 1 \\
\hline 16-Feb & 0 & 59 & 0 & 0 & 0 & 0 & 0 & 13 & 0 & 0 & 0 & 5 \\
\hline 23-Feb & 0 & 41 & 0 & 0 & 0 & 0 & 29 & 0 & 0 & 0 & 104 & 5 \\
\hline 28-Feb & 18 & 36 & 3 & 1 & 53 & 0 & 0 & 0 & 31 & 0 & 34 & 56 \\
\hline 07-Mar & 144 & 56 & 0 & 0 & 20 & 44 & 19 & 15 & 39 & 4 & 12 & 40 \\
\hline 15-Mar & 41 & 75 & 0 & 18 & 0 & 39 & 2 & 24 & 48 & 7 & 0 & 37 \\
\hline 22-Mar & 20 & 95 & 36 & 10 & 10 & 28 & 8 & 33 & & & 0 & 0 \\
\hline 29-Mar & 37 & 87 & 0 & 19 & 0 & 24 & 4 & 28 & & & 0 & 0 \\
\hline
\end{tabular}


TABLE II

Mean number of eggs (E), larvae and pupae (L), of Aedes aegypti and mean number of Mesocyclops annulatus adults (Cop) per container (C) during the period of higher mosquito larval density, from which $\operatorname{ST}(t, j)$ and $\operatorname{STM}(t)$

\begin{tabular}{|c|c|c|c|c|c|c|c|c|c|c|c|c|c|c|c|c|c|c|}
\hline \multirow[t]{2}{*}{ Date } & \multicolumn{4}{|c|}{ C 1} & \multicolumn{2}{|c|}{$\mathrm{C} 2$} & \multicolumn{3}{|c|}{ C 3} & \multicolumn{3}{|c|}{ C 4} & \multicolumn{3}{|c|}{ C 5} & \multicolumn{3}{|c|}{ C 6} \\
\hline & $\mathrm{E}$ & $\mathrm{L}$ & Cop & $\mathrm{E}$ & $\mathrm{L}$ & Cop & $\mathrm{E}$ & $\mathrm{L}$ & Cop & $\mathrm{E}$ & $\mathrm{L}$ & Cop & $\mathrm{E}$ & $\mathrm{L}$ & Cop & $\mathrm{E}$ & $\mathrm{L}$ & Cop \\
\hline 01-Feb & 63 & 3 & 17 & 14 & 3 & 2 & 54 & 0 & 3 & 20 & 0 & 41 & 141 & 6 & 8 & 0 & 0 & 3 \\
\hline 07-Feb & 221 & 21 & 71 & 33 & 2 & 5 & 0 & 10 & 7 & 0 & 28 & 8 & 6 & 8 & 8 & 0 & 0 & 7 \\
\hline 16-Feb & 0 & 0 & 23 & 40 & 70 & 2 & 3 & 0 & 16 & 2 & 0 & 36 & 31 & 11 & 8 & 43 & 0 & 12 \\
\hline 23-Feb & 56 & 0 & 10 & 28 & 34 & 3 & 106 & 0 & 11 & 99 & 0 & 28 & 0 & 5 & 6 & 0 & 4 & 14 \\
\hline 28-Feb & 86 & 8 & 14 & 53 & 45 & 3 & 74 & 0 & 20 & 39 & 1 & 33 & 24 & 2 & 3 & 16 & 0 & 10 \\
\hline 07-Mar & 0 & 27 & 16 & 77 & 80 & 1 & 0 & 11 & 21 & 45 & 0 & 32 & 10 & 27 & 1 & 0 & 1 & 20 \\
\hline 15-Mar & 78 & 22 & 14 & & & & 38 & 1 & 10 & 45 & 0 & 18 & 72 & 30 & 1 & 126 & 0 & 24 \\
\hline 22-Mar & 121 & 16 & 13 & & & & 7 & 0 & 22 & 7 & 4 & 8 & & & & & & \\
\hline 29-Mar & 0 & 2 & 21 & & & & 0 & 8 & 16 & 0 & 7 & 9 & & & & & & \\
\hline
\end{tabular}

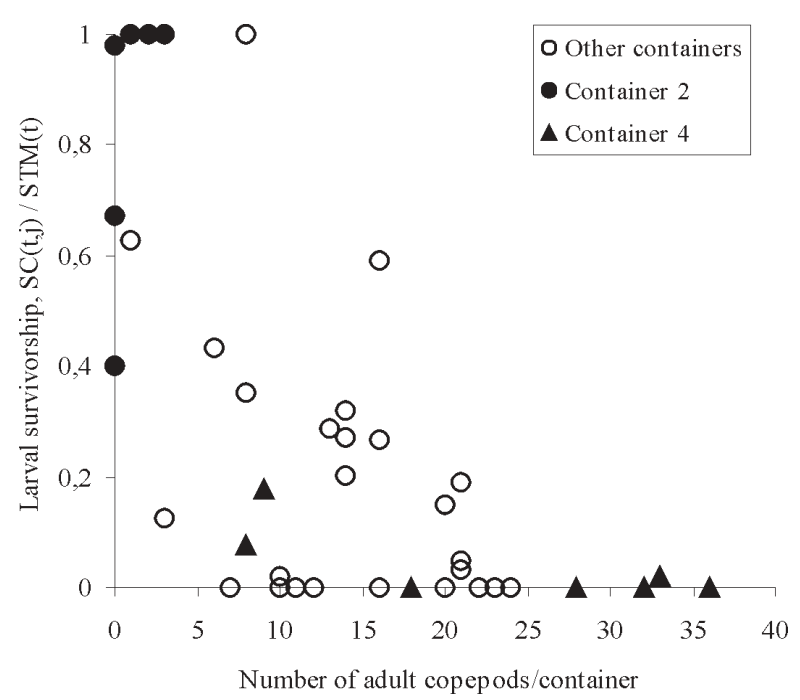

Fig. 3: estimated reduction of mosquito larval survivorship due only to predation by Mesocyclops annulatus, $\operatorname{SC}(t, j) / \operatorname{STM}(t)$, and the corresponding estimated copepod density at the beginning of the interval, $\mathrm{C}(t-1, j)$.

pod density began to decrease from the beginning of the experiment and during 51 days, up to a very low density (1 to 5 adults/container) which was maintained for 115 days. On the other hand, density in container 4 fluctuated between 16 and 50 adults/container during 142 days (approximately two weeks after the beginning of the experiment). Juvenile copepods were registered for the first time two weeks after the beginning of the experiment, when they represented $60 \%$ of all individuals (Fig. 4).

\section{DISCUSSION}

Copepods have been reported to be effective in controlling early-instar mosquito larvae. Biological control by copepod releases has been employed several times with varying results; notwithstanding the best results were obtained when the community participated (Marten et al. 1994, Gorrochoitegui et al. 1998).

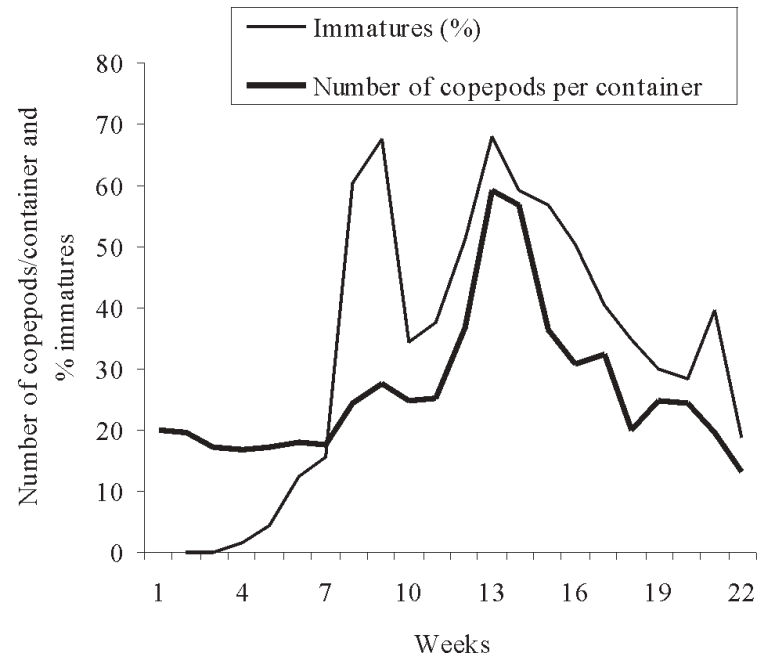

Fig. 4: mean number of preimaginal and adult Mesocyclops annulatus per container during the experiment and percentage of preimaginals M. annulatus.

Concerning biological control of mosquito larvae by Mesocyclops copepod species, it was mentioned that low temperatures and prolonged desiccation were limiting factors for copepod's effectiveness. A field study carried out in Panama by Schreiber et al. (1996) with M. longisetus Thiebaud, related the deficient control obtained to the low winter temperatures (below $10^{\circ} \mathrm{C}$ ), which severely reduced adult copepod abundance. Mechanisms of copepod resistance to desiccation have been reported for the copepodite and adult stages (Zhen et al. 1994). In Mexico, however, Gorrochotegui et al. (1998) found that the dry season considerably reduced $M$. longisetus survivorship, limiting its use in release programs for biological control of mosquito larvae developing in discarded tires and cemetery flower pots.

In the present study, the mean temperature during the spring-summer period fluctuated between 17 and $28^{\circ} \mathrm{C}$ and 
would not be a limiting factor for M. annulatus.

Regarding habitat desiccation, the water level of the containers was weekly controlled and water was added only if necessary. Observations in natural habitats made by Garcia and Micieli (1999) suggest that adult $M$. annulatus females would be able to persist during the desiccation period of temporary "ponds" if certain degree of humidity is maintained. In the study area, the mean monthly rainfall $(107.6 \mathrm{~mm})$ would prevent the complete desiccation of small containers like flower pods and abandoned tires, where A. aegypti lay eggs, at least during a great part of this mosquito period.

Micieli et al. (2002) found that M. annulatus fed on different species of algae and protozoan and small $A$. aegypti larvae. In this study we did not supply any kind of food to the containers, however the copepods were able to survive and reproduce during approximately 100 days without the resource represented by the mosquito larvae. The persistence of $M$. annulatus allowed a maximum spatial coincidence (6 containers) between $M$. annulatus and $A$. aegypti larvae in $89.9 \%$ of the interval (136 days) during the highest mosquito activity. At the end of the experiments the spatial coincidence was $50 \%$ (3 containers).

In the trials, the number of eggs in the control containers was smaller that in the containers with copepods. We did not make precise observations or experiments tended to elucidated the possible causes. However, TorresEstrada et al. (2001) studied the influence of the copepod $M$. longisetus on the selection of oviposition sites by $A$. aegypti. They found that gravid females were attracted to lay eggs by substances found in oviposition sites that contained or previously held copepods. Similarly, Ikeshoji et al. (1997) found that some bacterial products have been identified as attractants for gravid A. aegypti females.

Larval A. aegypti survivorship in the containers with copepods was significantly lower that in the control containers. Furthermore, A. aegypti mortality larval was higher in those containers with higher copepod density, and it was suggested that larval survivorship would be 0 when $M$. annulatus reach 23 adults/container.

Similar results were obtained by Micieli et al. (2002) in laboratory bioassays. Moreover, they suggest that the copepod remains at the bottom of the containers most of the time. The feeding behavior of these mosquito and copepod species may help increase the encounter opportunities with $A$. aegypti larvae by M. annulatus (Micieli et al. 2002).

The effectiveness of $M$. annulatus as a biological agent of mosquito control in Argentina resides in its ability to survive in a container during the oviposition period of $A$. aegypti, and it can therefore be considered as a promising biocontrol agent.

The next step is to evaluate $M$. annulatus in smallscale field trials against $A$. aegypti in environments such as cemeteries and public parks where the use of this method of mosquito control could be successful.

\section{ACKNOWLEDGMENTS}

To an anonymous referee for valuable comments on an earlier draft of this manuscript.

\section{REFERENCES}

Aviles G, Rangeon G, Vorndam V, Briones A, Baroni P, Enria D, Sabattini MS 1999. Dengue reemergence in Argentina. Emerg Infect Dis 5: 575-578.

Christopher SR 1960. Aedes aegypti (L.) the Yellow Fever Mosquito. Its Life History, Bionomics and Structure, Cambridge University Press, London, $721 \mathrm{pp}$.

Curto SI, Boffi R, Carbajo AE, Plastin R, Schweigmann N 2002. Reinfestación del territorio argentino por Aedes aegypti. Distribución geográfica (1994-1999). Actual Artrop Sanit Argent, Monogr, 2: 127-137.

Darsie RF, Mitchell CJ 1985. The mosquitoes of Argentina. Part I. Mosq Syst 17: 153-253.

Garcia JJ, Micieli MV 1999. Potencial de los microsporidios (Microspora) para el control de mosquitos (Diptera: Culicidae) en la Argentina. Rev Soc Entomol Arg 58: 34-41.

Garcia JJ, Micieli MV, Achinelly MF, Marti GA 2002. Establecimiento de una población de Aedes aegypti L. en La Plata. Actual Artrop Sanit Argent, Monogr. 2: 149-153.

Gorrochotegui-Escalante N, Fernandez-Salas I, Gomez-Dante $\mathrm{H}$ 1998. Field evaluation of Mesocyclops longisetus (Copepoda: Cyclopoidea) for the control of larval Aedes aegypti (Diptera Culicidae) in Northeastern Mexico. J Med Entomol 35: 699-703.

Ikeshoji T, Ichimoto I, Konishi J, Naoshima Y, Ueda H 1997. 7,11-dimethyloctadecane: an ovipositional attractant for Aedes aegypti by Pseudomonas aeruginosa on capric acid substrate. J Pest Sci 4: 187-194.

Lane J 1953. Neotropical Culicidae, Vols 1, 2, Fac Hyg Saude Publ, Univ São Paulo, Vol. II, p. 633-729.

Marten GG 1990. Evaluation of cyclopoid copepods for Aedes albopictus control in tires. J Am Mosq Control Assoc 6: 681-688.

Marten GG, Borjas G, Cush, M, Fernández E, Reid JW 1994. Control of larval Aedes aegypti in peridomestic breeding containers. J Med Entomol 31: 36-44.

Micieli MV, Marti G, Garcia JJ 2002. Laboratory evaluation of Mesocyclops annulatus (Wierzenjski, 1892) (Copepoda: Cyclopoidea) as a predator of containers breeding mosquitoes in Argentina. Mem Inst Oswaldo Cruz 97: 835-838.

Molyneux DH 1993. Control. In FEG Cox, Modern Parasitology, Blackwell Science, London, p. 243-263.

OPS 1990. Las Condiciones de la Salud en las Américas, Vol. 1, Organización Panamericana de la Salud, Geneve, 503 pp.

OPS 1995. Dengue y Dengue Hemorrágico en las Américas: Guías para su Prevención y Control, Organización Panamericana de la Salud, Geneve, $110 \mathrm{pp}$.

Rueda LM, Patel KJ, Stinner RE 1990. Temperature-dependent development and survival rates of Culex quinquefasciatus and Aedes aegypti (Diptera: Culicidae). J Med Entomol 27: 892-898.

Torres-Estrada JL, Rodríguez MH, Cruz-López L, ArredondoJimenez JI 2001. Selective oviposition by Aedes aegypti (Diptera: Culicidae) in response to Mesocyclops longisetus (Copepoda: Cyclopoidea) under laboratory and field conditions. J Med Entomol 38: 188-192.

Tun-Lin W, Burkot TR, Kay BH 2000. Effects of temperature and larval diet on developmental rates and survival of the dengue vector Aedes aegypti in north Queenland, Australia. Med Vet Entomol 14: 31-37.

Schaper S 1999. Evaluation of Costa Rican copepods (Crustacea: Eudecapoda) for larval Aedes aegypti control with special reference to Mesocyclops thermocyclopoides. J Am Mosq Control Assoc 15: 510-519.

Schreiber ET, Hallmon CF, Eskridge KM, Marten GG 1996. 
Effects of Mesocyclops longisetus (Copepoda: Cyclopidae) on mosquitoes that inhabit tires: influence of litter type, quality, and quantity. J Am Mosq Control Assoc 12: 688694.

Sokal RR, Rohlf FJ 1979. Biometría. Principios y Métodos Esta- dísticos en la Investigación Biológica, H Blume, Argentina, $832 \mathrm{pp}$.

Zhen T, Jenning CD, Kay BH 1994. Laboratory studies of desiccation resistance in Mesocyclops (Copepoda: Cyclopoida). J Am Mosq Control Assoc 10: 443-446. 